\title{
Determination of the Association between Perceived Stigma and Delay in Help-Seeking Behavior of Women with Breast Cancer
}

\author{
Sedigheh PAKSERESHTa, Sara TAVAKOLINIA ${ }^{b}$, Ehsan Kazemnejad LEILI ${ }^{\mathrm{c}}$
}

aSocial Determinants of Health Research Center, Reproductive Health Research Center, Department of Midwifery, School of Nursing and Midwifery, Guilan University of Medical Sciences, Rasht, Iran, ORCID: 0000-0002-9888-2130

bSchool of Nursing and Midwifery, Guilan University of Medical Sciences, Rasht, Iran, ORCID:0000-0001-7476-655X

'Department of Biostatistics, Social Determinants of Health Research Center, School of Nursing and Midwifery, Gilan University of Medical Sciences, Rasht, Iran, ORCID:0000-0002-9195-9094

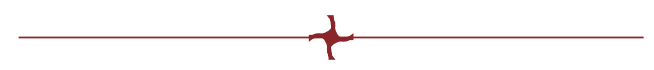

\begin{abstract}
Background: One of the leading causes of death in patients with breast cancer is delays in help-seeking, which is influenced by various factors, including social factors such as cancer stigma.

Objectives: This study aimed to determine the relationship between perceived stigma and delay in seeking help for women with breast cancer.

Methods: In this cross-sectional study, 140 women with breast cancer referred to Besat Clinic in Rasht, Iran, were included. The data gathering tools included a demographic questionnaire, a cancer stigma questionnaire and a delay questionnaire completed through interviews with patients. Data analysis was performed using SPSS software V.21 and the descriptive and inferential statistics were performed using correlation coefficient, chi-square test, logistic regression, Mann-Whitney U-test, and Kruskal-Wallis test.

Results: In this study, 72.1\% of patients were aged between 39 and 57 years, with a mean age of $47.99 \pm 8.03$ years; $34.3 \%$ and $16.4 \%$ of patients delayed seeking help between 30 and 90 days, and more than 90 days (with mean $\pm S D$ of $75.35 \pm 165.19$ ), respectively. Breast cancer stigma was present in $45 \%$ of patients. Delay in seeking help based on stigma was significant $(P<0.001)$. Due to multiple logistic regression, the association between stigma and delayed relief was significant $(P<0.01)$, so that in women suffering from breast cancer with stigma, the chance of delaying seeking help was 5.7 times (OR 5/706, Cl 95\% 1.381-23.572) higher than women without stigma.
\end{abstract}

\footnotetext{
Address for correspondence:

Sara Tavakolinia, Midwifery student (MSc)

Tel.: 0989356166517,Email: saratavakolinia67@yahoo.com

Article received on the $10^{\text {th }}$ of June 2021 and accepted for publication on the $29^{\text {th }}$ of September 2021
} 
Conclusions: Stigma may be a factor in delaying the screening of women with breast cancer. Therefore, it is recommended that the health care team considers stigma as one of the most important psychological aspects of breast cancer, which may have an impact on patients' delay in seeking help. It should also be considered in the process of diagnosis, treatment counseling, and patient follow-up.

Keywords: : social stigma, help-seeking behavior, breast cancer, women.

\section{BACKGROUND}

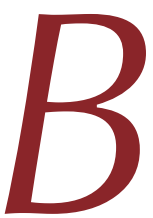
reast cancer is three times more common in developed countries than developing ones, even though the incidence rate is higher in developed countries, and the mortality rate is more significant in developing countries (1). In Iran, breast cancer is the most common malignancy in women, with 5,000 new cases known annually, and a number of new breast cancer cases in 2030 estimated to exceed 15,000 $(2,3)$.

Among the leading causes of mortality in patients with cancer, delayed help-seeking and delayed consultation are mentioned $(4,5)$. In this regard, general concepts of patient delay include: A) delay in assessment, when symptoms and disease are detected; B) patient's delay; the interval between inferring a disease and deciding to seek medical help; C) delay in taking action; the time interval between decision to seek medical help and taking action to enforce their decision to seek medical help.

The time interval between a patient's initial symptoms and the date when the first visit to a clinic is made is defined as the delay in seeking patient help (6). The suggested time period varies to define the delay time in help-seeking, and some described this interval above 30 days since the observation of symptoms till the patients' help-seeking time, while others pointed out a period above 90 days $(6,7)$. Also, some classify the elapsed time less than one month as "normal," 30-90 days as "delay," and more than 90 days as "long-term-delay" $(8,9)$.

Regarding the delay of patients seeking help in the literature, Attari's study found $52.5 \%$ of all investigated women with a delay of more than three months, and Dianatinasab's study 23.4\% $(4,10)$. In Mirfarhadi's study, 53\% of women reported a delay of more than one month, and in $31 \%$ of them, a delay of more than three months
(11). Moreover, in Mujar's study, a delay of more than three months was reported in $35 \%$ of patients (12). Also in Alam Khan's study, 30.01\% of patients were delayed (13).

Scientists have speculated different etiologies regarding delay in patients' help-seeking (14). Many factors, including personal causes as well as socio-cultural and economic factors, are involved in delay $(15,16)$. Furthermore, women's supportive behavior is affected by complex psycho-social, environmental, cultural, and cognitive causes (6).

Labeling or stigma is claimed to be an influential social determinant, which causes some patients' refusal of cancer screening, follow-up, and treatment $(17,18)$. Stigma is when the stigmatized person is discredited and blemished in his/her environment due to physical and mental distinctions. The term "stigma" is used for a feature or attribution which is considered extraordinarily notorious and disgraceful (19).

Cancer-related stigma is a significant sociomental issue that cancer patients may face within diagnosis and treatment. It can influence patients' daily life and is followed by various clinical outcomes and social consequences $(20,21)$.

The perception of stigma and its experience may be followed by treatment disobedience, feeling isolated, avoiding visiting health service providers, and low quality of life $(21,22)$. Dey et al state that "Stigma from breast cancer reflects a bad personality on women and makes them hide the symptoms of cancer" (23). Moreover, patients who are suffering from cancer may misperceive being stigmatized due to cancer. Fear and anxiety or avoiding patients with cancer can exacerbate the negative attitudes toward cancer (24). Fear and concern regarding the maintenance of personal privacy, stigma, and strict social taboo about cancer may strongly influence patients' tendency for seeking health information and willingness for receiving emotion- 
al support; even these concerns may deprive them of receiving emotional support, hence rendering them to feel socially isolated (22). Not only does breast-cancer-related stigma create a delay in the cooperation of women for treatment courses, but it also prevents the continuation and completion of treatment (25). The rate of stigma caused by breast cancer has been reported in various studies, including Cho et al stated that $30 \%$ of women with colorectal breast and gastric cancers experienced stigma in Korea (24). About a quarter of patients experienced high levels of stigma in India (26).

Delay in help-seeking of patients with cancer gives rise to numerous outcomes for them. Although studies regarding the causes of delay in cancer patients' help-seeking are widely extensive, the role of stigma in cancer (especially breast cancer) patients' delay has been explored to a lesser extent. The current study has been conducted for the same reason.

\section{METHODS}

Thesting his analytical cross-sectional study has been conducted on women with breast cancer who referred to or visited Be'sat Subspecialty Center for chemotherapy during 2018 in Rasht city, Iran.

The statistical criteria required for our population, allowing them to be eligible for the study, included Iranian nationality, presence of breast cancer (confirmed by mammography and biopsy), not having any other cancer, no cancer recurrence, and no metastasis, all of which being investigated according to the recorded documents and patients' statements.

Available sampling was performed between the $2^{\text {nd }}$ of May and June 3, 2018, according to the study of Carter Harris et al (17), and considering the Pearson coefficient $r=0.27$, confidence coefficient of $95 \%$, statistical test power of $90 \%$ and based on the formula; finally, the research selected a total number of 140 women after obtaining their written consent for participation. Questionnaires were filled out by interviewing each patient.

Data were collected from questionnaires, including the researcher's demographic questionnaire, composed of one part concerning socioindividual information and another one regarding family and individual cancer-related history, and the delay questionnaire (and its causes), retrieved from the study of Mirfarhadi et al (11), with questions about how a breast disease can be realized, what is the earliest symptom observed by the patient, the time of first suspected symptom of breast disease, elapsed time between the realization of breast cancer symptoms and the first visit to a healthcare practitioner, the first healthcare provider whom the patient visited, usage of other treatment approaches (before visiting a physician) and type of supplemental therapy. An interval of more than one month between patients' detection of first symptoms and the first medical consultation was regarded as a patient delay. The relevant items related to delay causes include the following 10 questions: financial restraints, time restrictions, fear of having severe diseases in the breast, fear of getting once specimen collected, no sense of urgency for a visit, fear of incurability of cancer, belief in predestination, fear of the treatments side effects, reassurance from others of the insignificance of the issue, and family's objections on treatment method and health center.

Initially, Cho J. et al (24) codified the cancer stigma scale (patient's version); later, Yılmaz assessed its validity and reliability in Turkey (21) and granted permission to us to use the questionnaire in the current study. The questionnaire is composed of 12 items in three domains: impossibilities of recovery (items 1-4), stereotypes of a cancer patient (items 5-8), and experience of social discrimination (items 9-12). The answers are designed based on a 4-point Likert scale and given a score of 1 to 4 as follows: 1 . Strongly disagree 2. Disagree 3. Agree 4. Strongly agree. The final stigma score was evaluated according to summed scores and their mean calculation through which the interpretation became possible. If the average of acquired scores (in all domains) was above or equal to 2.5 , it represented a negative attitude towards cancer and stigma. The Cronbach's alpha value of the scale was 0.79 in Cho's study and 0.88 in Ilmaz's study.

For scientific validity and reliability of both Cancer stigma questionnaire and Delay in help-seeking questionnaire (and its causes), the "content validity" method has been used. Hence, upon permission clearance from the author, the cancer stigma questionnaire was translated to Persian and then retranslated to English in the light of Lawshe's developed table. To measure 
content validity, the content validity index (CVI) and content validity ratio (CVR) were discussed by asking ideas from 10 professors. The mean CVR across the cancer stigma items and the causes of delay as another tool yielded a range of $0.8-1$ and $0.7-0.8$, respectively. "Test-retest reliability" was employed to assess the reliability of both causes of delay in help-seeking and stigma questionnaires. The questionnaires of 20 participants were filled out in two stages: first through a face-to-face interview, then confirmed after 10 days via phone call with the same subjects. Pearson ( $r$ ) correlation coefficient of both stages was $r=0.902(P<0.0001)$ across the causes of delay items and $r=0.847(\mathrm{P}<0.0001)$ across the stigma questionnaire items, representing statistical significance. Not to forget that the reliability coefficient for causes of delay in help-seeking as one of our tools and stigma tool obtained 99.2\%, $99.8 \%$; therefore, in terms of reliability, the engaged tools pass the credentials of trustworthiness for the study group.

\section{Ethical considerations}

All participants were informed about the research objectives. In addition to receiving informed written consent, they were assured that all their information was confidential, without including their names and personal details, unless the relevant authorities of the research environment wish to provide the study results.

\section{Statistical analysis}

In the present study, frequency distribution with a 95\% confidence interval was used to determine the stigma level and delay in help-seeking. Also, to assess perceived stigma related to breast cancer and delay in help-seeking, contingency coefficient and Chi-square test were employed to compare the variables (socio-individual history and cancer histories) with delay status; we used Mann Whitney $\mathrm{U}$ test and Kruskal-Wallis $\mathrm{H}$ test. Furthermore, the logistic regression model was applied in our multivariate analysis to associate delay with a stigma that balanced the socioindividual variables. Similarly, we utilized the logistic regression model to determine the predicting factors of delay. Statistical significance was considered when $\mathrm{P}<0.05$.

\section{RESULTS}

O ne hundred forty women with breast cancer with a mean age of $47.99 \pm 8.03$ (range 26-70 years) were included. The highest frequency in variables was for married women (82.9\%), educational level of "illiterate" or "knows reading \& writing" (52.9\%), and "housewife" status $(61.4 \%)$; while only $2.9 \%$ of subjects had an education profile related to medicine. Similarly, the most frequent choices for items of husband's education and occupation were "knows reading \& writing" (44\%) and "self-employment" (55.2\%), respectively. The majority of respondents reported "As much as needed "(53.6\%) for monthly income, "3-5 members" (72.9\%) for the number of supported members by family income, and "owning a house" $(75.7 \%)$ for homeownership item. Unfortunately, $53.6 \%$ of subjects did not have complimentary insurance.

Most participants did not report any history of complications in their breasts $(92.1 \%)$ and any family history of developing breast cancer (75.7\%). Among those who presented a family history of cancer $(24.3 \%), 44.1 \%$ died due to breast cancer. Note that $67 \%$ of patients repor-
TAB LE 1. Perceived stigma and its domains in the studied subjects

\begin{tabular}{|c|c|c|c|c|}
\hline \multirow{2}{*}{\multicolumn{2}{|c|}{ Domains of stigma }} & \multirow{3}{*}{$\begin{array}{l}\mathbf{N}(\%) \\
65(46.4)\end{array}$} & \multicolumn{2}{|c|}{$95 \%$ CI } \\
\hline & & & \multirow{2}{*}{$\begin{array}{l}\text { Lower } \\
38.3\end{array}$} & \multirow{2}{*}{$\begin{array}{l}\text { Upper } \\
54.7\end{array}$} \\
\hline Impossibility of recovery & Yes & & & \\
\hline & No & $75(53.6)$ & 45.3 & 61.7 \\
\hline \multirow[t]{2}{*}{ Stereotypes of cancer patients } & Yes & $120(85.7)$ & 79.2 & 90.8 \\
\hline & No & $20(14.3)$ & 9.2 & 20.8 \\
\hline \multirow[t]{2}{*}{ Experience of social discrimination by patient } & Yes & $28(20)$ & 14 & 27.2 \\
\hline & No & $112(80)$ & 72.8 & 86 \\
\hline \multirow[t]{2}{*}{ Perceived stigma } & Yes & $63(45)$ & 36.9 & 53.3 \\
\hline & No & $20(14.3)$ & 46.7 & 63.1 \\
\hline
\end{tabular}


TABLE 2. Comparison of the frequency distribution of delay time in help-seeking of the studied participants since the observation of symptom according to the status of stigma domains.

\begin{tabular}{|c|c|c|c|c|c|c|c|}
\hline \multirow{2}{*}{\multicolumn{3}{|c|}{ Status of stigma domains }} & \multicolumn{5}{|c|}{$\begin{array}{l}\text { Delay time in help-seeking of studied subjects since the } \\
\text { observation of symptom }\end{array}$} \\
\hline & & & \multirow{2}{*}{\begin{tabular}{|l|} 
0-29 days \\
$27(41.5)$ \\
\end{tabular}} & \multirow{2}{*}{\begin{tabular}{|l} 
30-90 days \\
$23(35.4)$ \\
\end{tabular}} & \multirow{2}{*}{$\begin{array}{l}\text { More than } \\
\mathbf{9 0} \text { days }\end{array}$} & \multirow{2}{*}{$\begin{array}{l}\text { Sum } \\
65(100)\end{array}$} & \multirow{2}{*}{$\begin{array}{l}\text { P value } \\
0.092 \\
\end{array}$} \\
\hline \multirow{2}{*}{$\begin{array}{l}\text { Impossibility of } \\
\text { recovery }\end{array}$} & Yes $^{\circ}$ & $\mathrm{n}(\%)$ & & & & & \\
\hline & NO & $\mathrm{n}(\%)$ & $42(56)$ & $25(33.3)$ & $8(10.7)$ & $75(100)$ & \\
\hline \multirow{2}{*}{$\begin{array}{l}\text { Stereotypes of } \\
\text { cancer patients }\end{array}$} & Yes & $\mathrm{n}(\%)$ & $53(44.2)$ & $45(37.5)$ & $22(18.3)$ & $120(100)$ & \multirow[t]{2}{*}{0.012} \\
\hline & NO & $\mathrm{n}(\%)$ & $16(80)$ & $3(15)$ & $1(5)$ & $20(100)$ & \\
\hline \multirow{2}{*}{$\begin{array}{l}\text { Experience of } \\
\text { social } \\
\text { discrimination } \\
\text { by patient }\end{array}$} & Yes & n (\%) & $12(42.9)$ & $11(39.3)$ & $5(17.9)$ & $28(100)$ & \multirow[t]{2}{*}{0.744} \\
\hline & NO & n (\%) & $57(50.9)$ & $37(33)$ & $18(16.1)$ & $112(100)$ & \\
\hline \multirow{3}{*}{$\begin{array}{l}\text { Perceived } \\
\text { stigma }\end{array}$} & Yes & $\mathrm{n}(\%)$ & $18(28.6)$ & $29(46)$ & $16(25.4)$ & $63(100)$ & \multirow[t]{3}{*}{0.001} \\
\hline & NO & $\mathrm{n}(\%)$ & $51(66.2)$ & $19(24.7)$ & $7(9.1)$ & $77(100)$ & \\
\hline & Total & $\mathrm{n}(\%)$ & $69(49.3)$ & $48(34.3)$ & $23(16.4)$ & $140(100)$ & \\
\hline
\end{tabular}

Mean of scoring of 2.5 and above has been considered as an indicator of stigma presence

ted no family history of other cancers in their maternal and paternal families. The majority of women had no history of mammography $(78.6 \%)$ or breast-sonography $(90.7 \%)$, with $70 \%$ of subjects having not visited a physician for breast examinations. Besides, the majority $(84.3 \%)$ came to know about the occurrence of a complication in their breast accidentally, and the feeling of a lump in their breast (53.6\%) was the chief symptom that convinced them to visit an specialist for further investigation. Other symptoms such as skin stretch $(5.7 \%)$, nipple retraction $(4.3 \%)$, and breast ulceration $(3.6 \%)$ were reported to a lesser extent. Regarding the first doctor visited by participants, $30.7 \%$ of women visited a gynecologist, $24.3 \%$ a general surgeon, $19.3 \%$ a general physician, and $17.9 \%$ a midwife. Also, most women (93.6\%) had not undergone any other therapy procedure.

Regarding the perceived stigma, $45 \%$ of all studied cases presented breast-cancer-related stigma (Table 1). The results represented the frequency distribution of perceived stigma according to individual and social variables; primary diagnostic methods were not statistically significant.

Regarding the days of delay in help-seeking since the observation of the first symptom, $49.3 \%$ of respondents reported a delay of "less than
30 days", $34.3 \%$ a delay of "30-90 days," and only few $(16.4 \%)$ more than 90 days. Also, to understand how statistics changes in items of socio-individual variable, cancer histories compare to delay status, we concluded that only the variables represented by "possessing complementary insurance" $(P=0.033)$, "the presence of ulceration in the breast" $(\mathrm{P}=0.011)$ and the first referred person being a health care practitioner $(P=0.012)$ were statistically significant.

From one perspective, "30-90 days" of delays was more common among women with stigma (46\%) than those without stigma (9.1\%) (Table 2). Also, delay in help-seeking due to stigma has been seen in $71.4 \%$ of participants $(\mathrm{P}=0.001)$.

With respect to predicting factors being effective on delay in help-seeking, the following causes are presented with statistical significance in both groups of women with and without delay: I was afraid of specimen collection $(P=0.001)$; I did not sense the urgency to do it $(\mathrm{P}=0.001)$; I was afraid that my diseases be incurable, and I did not refer $(\mathrm{P}=0.001)$; I was afraid of the side effects of the treatment $(\mathrm{P}=0.001)$; and others ensured me that there is no severe problem $(\mathrm{P}=0.031)$.

The association of stigma with delay in helpseeking after controlling the individual and social variables with statistical significance less than 
TAB LE 3. Regression coefficient and relative estimated chance of stigma effects on a delay time exceeding 30 days after balancing the effect of individual socio-individual variables and cancer histories, in the logistic regression model

\begin{tabular}{|c|c|c|c|c|c|c|c|}
\hline \multicolumn{2}{|c|}{ Socio-individual variables } & \multirow{3}{*}{$\begin{array}{l}\text { Regression } \\
\text { coefficient }\end{array}$} & \multirow{3}{*}{$\begin{array}{l}\text { SE } \\
0.168\end{array}$} & \multirow{3}{*}{$\begin{array}{l}\text { P value } \\
0.294\end{array}$} & \multirow{3}{*}{$\begin{array}{l}\text { Relative } \\
\text { chance }\end{array}$} & \multicolumn{2}{|c|}{$95 \%$ CI } \\
\hline & & & & & & \multirow{2}{*}{$\begin{array}{l}\text { Lower } \\
0.603\end{array}$} & \multirow{2}{*}{$\begin{array}{l}\text { Upper } \\
1.165\end{array}$} \\
\hline Value & Age & & & & & & \\
\hline \multirow[t]{9}{*}{$\begin{array}{l}\text { primary } \\
\text { model }\end{array}$} & $\begin{array}{l}\text { Family history of } \\
\text { developing breast cancer }\end{array}$ & 0.603 & 0.92 & 0.512 & 1.828 & 0.301 & 11.094 \\
\hline & $\begin{array}{l}\text { Possessing a history of } \\
\text { developing other cancers } \\
\text { in the maternal and } \\
\text { paternal families }\end{array}$ & 1.449 & 0.838 & 0.084 & 4.258 & 0.824 & 21.993 \\
\hline & Breast mass/lump & -0.228 & 0.314 & 0.780 & 0.796 & 0.161 & 3.929 \\
\hline & $\begin{array}{l}\text { Age at the onset of the } \\
\text { menstrual cycle }\end{array}$ & 0.025 & 0.301 & 0.933 & 1.026 & 0.569 & 1.849 \\
\hline & Number of pregnancies & 0.025 & 0.488 & 0.959 & 1.026 & 0.394 & 2.672 \\
\hline & Number of deliveries & 0.202 & 0.5 & 0.686 & 1.224 & 0.459 & 3.263 \\
\hline & $\begin{array}{l}\text { The elapsed time since the } \\
\text { end of menopause (years) }\end{array}$ & 0.017 & 0.086 & 0.839 & 1.018 & 0.860 & 1.204 \\
\hline & Stigma & 1.948 & 0.815 & 0.017 & 7.017 & 1.420 & 34.683 \\
\hline & Constant number & 6.489 & 8.691 & 0.455 & 657.989 & & \\
\hline \multirow[t]{3}{*}{$\begin{array}{l}\text { Final } \\
\text { model }\end{array}$} & $\begin{array}{l}\text { History of developing } \\
\text { other cancers in the } \\
\text { maternal or paternal } \\
\text { families }\end{array}$ & 1.435 & 0.722 & 0.047 & 4.201 & 1.019 & 17.311 \\
\hline & Stigma & 1.742 & 0.724 & 0.016 & 5.706 & 1.381 & 23.572 \\
\hline & Constant number & -1.303 & 0.653 & 0.046 & 0.272 & & \\
\hline
\end{tabular}

0.25 in univariate analysis was again with $\mathrm{P}=0.016$ statistically significant (OR 5.706, Cl 95\% 1.38-23.57), and the likelihood of delay in help-seeking cancer women with stigma was 5.7 times greater than those without stigma. Besides, there was an estimated 4.2 times increase in the chance of delay when there was no history of developing other cancers in maternal and paternal families (OR 4.201, Cl 95\% 1.019-17.311) (Table 3).

Similarly, logistic regression model based multifold analysis of causes of delay in helpseeking, fear of sampling $(P=0.021)$, lack of realization of urgency $(\mathrm{P}=0.001)$, and belief in unavoidable predestination and determinism $(\mathrm{P}=0.41)$ were considered the three most important causes of delay in help-seeking. In other words, with increased scores of "fear of sampling" and "lack of realization of urgency in punctual visit", there was an elevated chance of delay, and by each increased score, the relative delay due to fear of specimen collection and no sense of urgency in the on-time visit was "OR 1.15, $\mathrm{Cl} 95 \%$ 1.021-1.298" and "OR 1.695, Cl 95\% 1.403-2.049", respectively.

\section{DISCUSSION}

This study investigated the relationship between perceived stigma and delay in helpseeking behavior among women with breast cancer. The results showed that the delay in seeking help from patients was associated with stigma, and the chance of delay in seeking help from women with stigma breast cancer was hi- 
gher than those without stigma. In line with the present study results, Meacham et al described a relationship between understanding breast cancer stigma with delay in seeking help, patient interaction with breast and cervical cancer, completion, and continuation of treatment (25). Steiness et al also stated that fear and stigma were among the most commonly seen beliefs and attitudes of breast cancer patients, and represented an obstacle to receiving timely health care. These ideas affected the delay in patient's decision as well as the family's beliefs and attitudes (27). The high level of perceived cancer stigma was associated with increasing the number of days seeking help following the onset of symptoms (17). Scott's study found that understanding stigma was a barrier to seeking patient help and delaying the diagnosis and treatment of cancer (28). Evaluating the early symptoms and seeking help behavior, it can be inferred that cultural and social beliefs play a significant role in the sanitary behavior of cancer patients. Stigma, taboo, and fear of women toward adverse conduct of society could influence delay time in seeking help and lead to delayed help-seeking in women.

The results of the present study showed that $45 \%$ of respondents had a stigma. Also, in a study from Thailand, women with breast cancer reported stigma due to the nature of the disease and its treatment and complications (29). Cho has reported that patients with breast cancer and concomitant stomach, colorectal or genital cancers have all had a stigma and negative attitudes toward cancer (24). A study from India and Africa also reported stigma in breast cancer patients $(26,30)$. Moreover, other studies based on studied subjects (cancer patients and patients with other diseases) and the type of utilized tools also reported different degrees of perceived stigma. This is to the extent that negative attitude and stigma among community individuals was observable toward cancer patients (31). Thus, stigma was reported in patients with ether cervical cancer and HIV (Rosser's study on Kenyan women) (32), or chronic diseases (in patients from Cambodia, Malaya, and Vietnam) (33). The mixed study results could be derived from the type, quality, and severity of the disease, research tools, cultural and social differences, development of a society, knowledge level, and awareness.
The findings of the current study show that $34.73 \%$ of participants delayed their help-seeking by $30-90$ days and $16.4 \%$ more than 90 days. Although the rate of delay in our study was lower than that reported by Mirfarhadi (more than 30 days and more than 90 days, 53\% and $31 \%$, respectively) (11), our latency was higher than in other countries; thus, in Turkey, a delay by more than 30 days (16.7\%) and more than 90 days $(5.3 \%)$ was reported (8), and in Estonia by more than three months (17\%) (7). The difference in type, quality, and severity of the diseases across studies, time of conducting the study, practical definition of "delay time" in the study, level of public awareness of the society in the study, and degree of accessibility of healthcare experts for patients are among the reasons influencing the different results of delay in helpseeking.

The results showed that among individual and social variables and cancer records, lack of supplementary insurance was associated with a delay in seeking help from women, as found by other studies too $(6,11,34)$. It seems that insurance support for cancer patients is necessary for the early referral of these patients. Our findings have also shown that the first symptoms of breast cancer (perceived by a patient) had a significant relationship with the patient's delay in seeking help, so that patients with breast ulcers, on average, had more delay in seeking help than other symptoms. In the Innos's study, a lack of breast mass was associated with patient's delay in seeking help (7). Macleod et al reported that unspecific and vague symptoms might have increased the risk of delay in seeking help (35). Similarly, Meechan et al stated that the delay period to seek help was shorter in the women who felt a breast lump than that those with other symptoms (36). Regarding this association, it can be inferred that the more commonly seen symptoms, including feeling pain and lump in the breast, are more alarming for women to doubt about breast cancer, and more unspecific symptoms draw less attention, and if considered to be necessary, it leads to an increase in the period of delay in seeking help.

The above study results showed that women referred to an internal medicine specialist on their first visit had a long delay seeking help. According to Shieh S-H et al, patients preferred to be examined by well-known physicians, which 
explained why patients' delay time prolongs (37), while Brinton reported that seeking help from people other than specialists and nurses prolonged delays in help-seeking (38). Regarding the underlying causes, causes like unawareness of patients to refer to the related physician, inaccessibility to a general surgeon, gynecologist, or midwife could be argued.

In multiple analyses, the three most important causes of delay in seeking help included fear of sampling, lack of urgency to see a doctor, belief in lack of change of fate, and appreciation. Higher scores of items represented by fear and no sense of urgency in the on-time visit meant that the chance of delay rose, while higher scores in the belief of predestination and determinism were translated in a reduced chance of delay in seeking help. In the study of Mirfahadi, it has been mentioned that the most important causes of delay more than one month in seeking help according to patients' estimation, are as follow: no sense of urgency in referring and urgent visiting by a physician, fear of disease and cancer diagnosis and financial problems (11). Among the mentioned causes, the current study has not identified the "financial problem" to be statistically significant. Due to health policy improvements in our country, all participants were $100 \%$ covered by insurance, whereas, when Mirfarhadi et al were conducting their study, full coverage of insurance was not available. In Gözüm's study, fear and anxiety, shame, refusal, and inattention to symptoms of breast cancer delayed seeking help from patients with breast cancer (8). O'Mahony has also determined the fear as a contributing factor and a cause for delay in helpseeking of women (39). Fear of cancer diagnosis, fear of losing breasts, and fear of radiotherapy were either obstacles toward breast cancer screening in a group of women or contributor factors in another group (40). In the current study, higher scores in predestination and determinism have reduced the chance of delay.

Contrary to our study, Gözüm reported that beliefs in predestination and determinism had led to delay in seeking help (8). Likewise, Gullatteet et al found no association between practicing a religion and beliefs in predestination and determinism, on one hand, and timing of help-seeking behavior, on the other hand (41). The association of "belief in the destination (and destiny)" with a delay has been differently re- ported by Gözüm and Gullate and by us in the current study. The underlying cause could be attributed to the type of beliefs, cultural and even religious differences of explored societies.

Also, in the present study, in logistic regression, the absence of a history of other cancers in maternal or paternal family increased the chances of delaying seeking help, whereas Gangane (5) and Gözüm (8) declared that family history of developing other cancers did not play any role in women's help-seeking behavior. Moreover, Aleem Khan (6) and Gueye (42) argued that lack of family history of developing breast cancer regarding delay had a statistical significance, and a delay followed it in seeking help. On the contrary, in the studies of Gözüm(8) and Odongo (43) as well as the current study, there was no evidence of an association between these two. Generally, it seems that insufficient knowledge of patients about contributing factors to breast cancer and lack of history of inheritance of other cancers in the family may form false confidence in immunity to cancer and increases patients' delay in seeking help.

\section{Study limitations}

In this study, sampling was based on only 140 patients referred to a government center, which cannot be generalized to all patients with breast cancer. It is better to do multicenter studies with a larger sample size on patients in private centers. The present study was quantitative. The questionnaire completion enabled the researcher to learn that interviewing and conducting a qualitative study was a better solution in the effort to obtain respondents' correct answer to questions; also, many of patients' conversations and feelings during the completion of the questionnaire could not be expressed in quantitative questions, which lead to the conclusion that it would be better to conduct a qualitative study on these patients.

\section{CONCLUSION}

The perception of stigma related to breast cancer and other causes can lead to patients' delay in seeking help. Concerns in the association of breast cancer with its high stigma could negatively influence various aspects of patients' life and health behaviors to a wide extent. Those who have breast cancer ignore their early symp- 
toms due to stigmatization concerns, hence the delay in seeking help trying to hide their disease. Patients' delay could have adverse effects on their prognosis, treatment, and even surveillance. Therefore, the results of this study can not only help providing more information and awareness to healthcare suppliers, but also draw their attention towards the essential psychological dimension of breast cancer and presence of stigma, which they may consider in offering clinical and counseling services to women. Also, presenting the results of this study to managers and policymakers of health services by emphasizing this dimension and its effect on early referral of breast cancer patients in the development of training and counseling programs for the health team and clients can be helpful.

Conflicts of interest: none declared.

Financial support: The Master Research Project from Guilan University of Medical Sciences and Social Determinants of Health Research Center (SDHRC) funded this research project.

Ethics standard: Ethical permission was obtained from the Research Ethics Committee of Guilan University of Medical Sciences Code: IR. GUMS.REC.2017.536)

Acknowledgments: We would like to thank all who participated in this study and all people who helped us.

\section{REFERECES}

1. Mahshid GH, Neda MF, Efat DV. Epidemiology, incidence and mortality of breast cancer in Asia.

Asian Pac J Cancer Prev 2016;17:47-52.

2. Fatemeh AV, Mireille B, Mohsen M, et al. The effect of demographic and lifestyle changes on the burden of breast cancer in Iranian women: a projection to 2030. The Breast 2013;22:277-281.

3. Bibihajar Z, Afsaneh K, Ahmad KH, et al. Breast cancer trend in Iran from 2000 to 2009 and prediction till 2020 using a trend analysis method. Asian Pac J Cancer Prev 2016;17:1493-1498.

4. S Maryam A, Gitti OZ, Mahnaz S, et al. Study of Relationship Between Illness Perception and Delay in Seeking Help for Breast Cancer Patients Based on Leventhal's Self-Regulation Model. Asian Pac J Cancer Prev 2016;1:167-174.

5. Nitin G, Anshu, Shiva M, et al. Prevalence and risk factors for patient delay among women with breast cancer in rural India. Asia Pac J Public Health 2016;28:72-82.

6. Khan MA, Shafique $S$, Shahzad MF. Presentation Delay in Breast Cancer Patients, Identifying the Barriers in North Pakistan. Asian Pac J Cancer Prev 2015;16:377-380.

7. Kaire I,Peeter $P$, Vahur V, et al. Identifying women at risk for delayed presentation of breast cancer: a cross-sectional study in Estonia. BMC Public Health 2013;13:200-220.

8. Gözüm S, Tuzcu A. Elapsed Time Between the First Symptoms of Breast Cancer and Medical Help-Seeking Behavior and the Affecting Factors. Cancer Nurs 2018;41:E21E29.

9. Sedighe PS, Gopal KI, Suneela G, et al. Stage at diagnosis and delay in seeking medical care among women with breast cancer, Delhi, India.

Iran Red Crescent Med J 2014;16:120-125.

10. Mostafa D, Mohammad F, Mohammad MP, et al. Impact of social and clinical factors on diagnostic delay of breast cancer: A Cross-sectional Study. Med 2016;95:38-45.

11. Nastaran MF,Atefeh GH, Mahahat $\mathrm{KH}$, et al. Predictive Factors for Diagnosis and Treatment Delay in IranianWomen with Breast Cancer.

Nurs Midwifery Stud 2017;1:90-101.

12. Noor Mastura MM, Mazrah D, Nor Aina E, et al. Complementary and alternative medicine (CAM) use and delays in presentation and diagnosis of breast cancer patients in public hospitals in Malaysia.

PLoS One 2017;12:e0176394.

13. Mohammad AK,Sheharyar $H$, Sundas I, et al. Presentation delay in breast cancer patients and its association with sociodemographic factors in North Pakistan. Chin J Cancer Res 2015;27:288-298.

14. Claire EJ, Jill M, Ruth HJ, et al. A systematic review of barriers to early presentation and diagnosis with breast cancer among black women. BMJ Open 2014;4:e004076.

15. Ketan SH,Ainhoa C, Lawrence NS, et al. A systematic review of barriers to breast cancer care in developing countries resulting in delayed patient presentation. J Oncol 2012;12:95-110.

16. Ebrahim MN. Illness perception and delay in seeking help in women with breast cancer symptoms: An appraisal of self-regulation model. J Behav Sci 2008;2:271-282.

17. Lisa CH. Lung cancer stigma as a barrier to medical help-seeking behavior: Practice implications.

J Am Assoc Nurse Pract 2015;27:240-245.

18. Daisuke F, Nao H. Cancer Stigma and its Health Consequences. Curr Breast Cancer Rep 2015;7:143-150.

19. Erving G. Stigma:notes on the management of spoiled identity: Simon and Schuster, 2009.

20. Hyang SS, Myeong JC,Hye YK. Reliability and validity of the Korean version of the cancer stigma scale. J Korean Acad Nurs 2017;47:121-132.

21. Medine Y, Gulcin D,Filiz I, et al. Reliability and validity study of a tool to measure cancer stigma: Patient version. Asia Pac J Oncol Nurs 2017;4:155-165.

22. Alicia KM,Sarah AS, Clara M, et al. Factors Influencing Medical Information Seeking Among African American Cancer Patients. J Health Commun 2002;7:205-219.

23. Subhjit D, Surabhi S, Atri M. Breast cancer awareness and prevention behavior among women of Delhi, India: identifying barriers to early detection. Breast Cancer (Auckl) 2016;10:BCBCR S40358.

24. Juhee CH, Eun KC,So YK, et al. Association between cancer stigma and depression among cancer survivors: a nationwide survey in Korea. Psychooncology 2013;22:2372-2378.

25. Elizabeth M, Jackson O, Gertrude N, et al. Exploring stigma as a barrier to cancer service engagement with breast cancer survivors in Kampala, Uganda. Psychooncology 2016;25:1206-1211.

26. Lopamudra T, Soumitra SD, Sajit KA, et al. Stigma perceived by women following surgery for breast cancer. Indian journal of medical and paediatric oncology: 
Indian J Med Paediatr Oncol 2017;38:146-150.

27. Heather SS, Michelle VG, Homaira P, et al. Barriers to care for women with breast cancer symptoms in rural Bangladesh. Health Care Women Int 2018;39:536-554.

28. Nicola s, Melanie C, Mayanne L, et al. Stigma as a barrier to diagnosis of lung cancer: patient and general practitioner perspectives.

Prim Health Care Res Dev 2015;16:618-622.

29. Suwankhong $D$, Liamputtong $P$. Breast cancer treatment: experiences of changes and social stigma among Thai women in southern Thailand.

Cancer Nurs 2016;39:213-220.

30. Timothy DVD, Solomon B, Claire H, et al. A mixed-method assessment of beliefs and practice around breast cancer in Ethiopia: implications for public health programming and cancer control. Glob Public Health 2011;6:719-731.

31. Juhee $\mathrm{CH}$, Katherine $S$, Eun $\mathrm{KC}$, et al. Public attitudes toward cancer and cancer patients: a national survey in Korea. Psychooncology 2013;22:605-613.
32. Joelle R, Betty N, Megan JH.

Cervical Cancer stigma in rural Kenya: what does HIV have to do with it? J Cancer Educ 2016;31:413-418.

33. Karl P, Supa P. Anticipated stigma in chronic illness patients in Cambodia, Myanmar and Vietnam. Nagoya J Med Sci 2016;78:423-430.

34. Karla US, Claudia B. Breast cancer delay: a grounded model of help-seeking behaviour.

Soc Sci Med 2011;72:1096-1104

35. Macleod U, Mitchell E, Burgess C, et al. Risk factors for delayed presentation and referral of symptomatic cancer: evidence for common cancers. Br J Cancer 2009;101:S92-S101.

36. Geraldine M, John C, Keith JP. The relationship of symptoms and psychological factors to delay in seeking medical care for breast symptoms. Prev Med 2003;36:374-378.

37. Shwn HS, Vivian CRH, Shu HL, et al. Delayed time from first medical visit to diagnosis for breast cancer patients in Taiwan. J Formos Med Assoc 2014;113:696-703.
38. Louise B, Jonine F,Ernest A, et al. Factors contributing to delays in diagnosis of breast cancers in Ghana, West Africa. Breast Cancer Res Treat 2017;162:105-114.

39. Mairin OM, Josephine $\mathrm{H}$,

Gelardine MC. Women's help seeking behaviour for self discovered breast cancer symptoms. Eur J Oncol Nurs 2011;15:410-418.

40. Ayla T, Zuhal B. Barriers and facilitators to breast cancer screening among migrant women within Turkey. J Transcult Nurs 2015;26:47-56.

41. Mary MG, Otis B, Arita $K$, et al. Religiosity, spirituality, and cancer fatalism beliefs on delay in breast cancer diagnosis in African American women. J Relig Health 2010;49:6272.

42. Mamour G, Serigne MKG,Moussa $D$, et al. Sociodemographic factors associated with delays in breast cancer. Open J Obstet Gynecol 2017;7:455-463.

43. Odongo J, Makumbi T, Kalungi S, et al. Patient delay factors in women presenting with breast cancer in a low income country. BMC Res Notes 2015;8:467-473. 